PAPER

\title{
Antinuclear antibodies define a subgroup of paraneoplastic neuropathies: clinical and immunological data
}

\author{
M Tschernatsch, E Stolz, M Strittmatter, M Kaps, F Blaes
}

J Neurol Neurosurg Psychiatry 2005;76:1702-1706. doi: 10.1136/jnnp.2003.033225

See end of article for authors' affiliations

....................

Correspondence to: Dr F Blaes, Department of Neurology, Justus-LiebigUniversity, Am Steg 14, 35385 Giessen; franz. blaes@neuro.med. uni-giessen.de

Received

25 November 2003

Revised version received 21 March 2005

Accepted 24 April 2005
Objective: Paraneoplastic neuropathy is a clinical and immunological heterogeneous disorder and attempts have been made to classify subgroups of this disease. Only 30-50\% of the clinical defined cases have antineuronal antibodies.

Methods: The clinical and immunological features of 36 patients with paraneoplastic neuropathy from the authors' database were analysed including the type and course of the neuropathy, associated tumours, and the presence of antineuronal and other autoantibodies.

Results: Antineuronal antibodies were detected in $17 / 36$ patients $(47 \%)$ and anti-Hu was the most frequent antineuronal antibody. Nine patients had high titre antinuclear antibodies (ANA, median titre 1/ 1000) without antineuronal antibodies. ANA reactivities were different in most patients. Comparison of the ANA positive and ANA negative patients revealed that ANA positive paraneoplastic neuropathy is more frequently associated with breast cancer but is not associated with lung cancer $(p<0.05)$. The main clinical type in these patients was sensorimotor neuropathy. No ANA positive patient had central nervous system involvement. Although the Rankin score at the time of diagnosis was not different, the functional outcome in ANA positive patients was better than in ANA negative patients $(p<0.05)$.

Conclusions: Paraneoplastic neuropathy is a heterogeneous disorder. ANA may define a subgroup of paraneoplastic neuropathy with different clinical and immunological features and may be related to better prognosis of the neuropathic symptoms.
$\mathrm{P}$ araneoplastic neurological syndromes (PNS) are diseases associated with tumours of the nervous system and are not caused by a local effect of the tumour or its metastases. PNS may affect any structure of the nervous system from brain to muscle. ${ }^{1}$ Cross-reactive autoantibodies directed against tumour cells and nervous system structures have been described, and thus an autoimmune aetiology of PNS has been discussed. ${ }^{2}$

Neuropathies are frequently associated with cancer, not only as a PNS, but also often caused by treatment toxicity, cachexia, or metabolic disturbances. "True" paraneoplastic neuropathies are rare and represent a clinically and immunologically heterogeneous group. ${ }^{3}$ Although neuropathies involving only one system (pure motor, sensory, or autonomic neuropathy) are more often associated with cancer, almost every clinical type of neuropathy has been described as a PNS. ${ }^{3}$

Different studies have reported paraneoplastic neuropathies to be associated with a variety of antineuronal antibodies, such as anti-Hu, anti-CRMP5, or ANNA-3. ${ }^{5-7}$ However, only $50-60 \%$ of paraneoplastic neuropathies have detectable antineuronal antibodies. ${ }^{3}$ Attempts have been made to classify paraneoplastic neuropathies by the clinical syndrome, the associated antineuronal autoantibodies, or the clinical course of the neuropathy. ${ }^{3}$

In the present retrospective study from our database we analysed data on patients with clinical suspected paraneoplastic neuropathy and identified a subgroup of patients with antinuclear antibody (ANA) positive neuropathy. Here we report the clinical and immunological features of these patients.

\section{PATIENTS AND METHODS}

\section{Patients}

The patients included in the present study were selected from our neuroimmunological database, which, between January 1998 and December 2002, included 58 patients with PNS. The database includes all patients from four neurological departments with a request for autoantibody search. The patients with paraneoplastic neuropathy included in this study had clinical and electrophysiological signs of neuropathy, a histologically proved cancer, and no other causes for their neuropathy. Also, there had to be a short time interval between the onset neuropathy and the diagnosis of the tumour disease $( \pm 4$ years according to the guidelines of the German Neurological Society). According to the recommended criteria for the diagnosis of PNS recently published in this journal, ${ }^{8} 18$ patients had definitive and 14 patients had possible paraneoplastic neuropathy, and 4 patients could not be classified owing to lack of information about the clinical course and treatment. In addition, the patient's serum had to be available. The neurological disability was measured using the modified Rankin score (RS). ${ }^{9}$ Improvement or deterioration was defined by a change of at least 1 point on the RS.

The local ethical committee approved the study and the patients' sera (which had been taken for routine diagnostic purposes) was stored and analysed after informed consent.

\section{Methods}

Autoantibodies were detected by indirect immunofluorescence (IFT) and western blot analysis. We used a commercially available kit (Euroimmun, Lübeck, Germany) according to the manufacturer's instructions for the detection of antinuclear and antineuronal antibodies by IFT. In brief, unfixed frozen sections of Hep-2 cells, cerebellum, cerebral cortex, and gut were incubated with the serum sample for three hours at room temperature. After washing in phosphate-buffered saline/Tween $0.2 \%$ (PBS-Tween) the sections were exposed to FITC-labelled goat antihuman IgG (Dako, Hamburg, Germany) for 30 minutes. A Zeiss

Abbreviations: ANA, antinuclear antibodies; IFT, indirect immunofluorescence; PNS, paraneoplastic neurological syndrome(s); RS, Rankin score 
immunofluorescence microscope was used by two independent investigators to view the immunofluorescence. The initial serum dilution was $1 / 10$ for ANA and $1 / 32$ for antineuronal antibodies; all samples were diluted to endpoint titres in IFT. For negative controls we used slides incubated with buffer only and buffer with the FITC-labelled antibody, respectively. Sera known to be positive for high titre ANA and two antineuronal (anti-Hu) antibody positive sera were used as positive controls.

Western blotting using human cerebellum as well as recombinant $\mathrm{HuD}$ and Yo proteins was carried out as described previously with slight modifications. ${ }^{10}$ In brief, human cerebellum was homogenised in PBS, solubilised in LDS sample buffer (Invitrogen; Karlsruhe, Germany), and heated to $100{ }^{\circ} \mathrm{C}$. The proteins were separated by electrophoresis on a preparative $4-12 \%$ gradient polyacrylamide gel (NUPAGE gel, Invitrogen). Proteins were transferred to nitrocellulose in a tank blot unit at $500 \mathrm{~mA}$ for 1 hour. The nitrocellulose was cut into strips. Every strip was incubated with the patient's serum (initial 1:100 diluted in PBS containing $2 \%$ dry milk) for one hour and washed three times in PBS. To visualise specific reactions, we used an alkaline phosphatase marked goat antihuman IgG antibody with BCIP-NBT (Calbiochem; Bad Soden, Germany) as a substrate.

To test for specific ANA reactivities we used a commercially available blot with recombinant or affinity isolated antigens (Euroimmun) including the following antigens: ribosomal $\mathrm{P}$ protein, histone, dsDNA, CENP-B, Jo-1, Scl-70, SSA, Ro52, SSB, Sm, and nRNP. In addition, patients had been tested for anti-CENP-F autoantibodies on a western blot using affinitypurified CENP-F protein. Sera were considered positive for antineuronal antibodies if the titre in the IFT was $\geqslant 1: 100$ and cerebellum specific reactions in the western blot were detectable. ANA were considered positive if the serum titre was $\geqslant 1: 100$ (IFT on Hep-2 cells).

\section{Statistical analysis}

We used Fisher's exact test to compare clinical features/ frequencies between the groups. Differences in tumour type distribution, type of neuropathy, and course of neuropathy were tested using $\chi^{2} 2 \times 6,2 \times 4$, and $2 \times 3$ tables with Yates' correction. For the analysis of other parameters we used the $t$ test. A p value $<0.05$ was considered significant.

\section{RESULTS}

Of 58 patients, 36 (62\%; 22 men, 14 women; mean (SD) age 61.9 (10.1) years) had neuropathy. Most of the patients had sensorimotor neuropathy (23/36). The others had sensory neuronopathy (4/36), polyradiculitis (3/36), motor neuropathy $(2 / 36)$, multiplex neuritis $(2 / 36)$, autonomic neuropathy $(1 / 36)$, and chronic inflammatory demyelinating neuropathy $(1 / 36)$. Autonomic disturbances were found in $38 \%$ of the patients $(10 / 26$, information not available for 10 patients). Eight patients (22\%) had involvement of the central nervous system. The most frequent tumour associated with the paraneoplastic neuropathy was lung cancer (36\%), mainly small cell lung cancer (77\% of the lung cancer). The tumour distribution is shown in table 1 .

\section{Autoantibody findings}

Antineuronal antibodies were detected in 17/36 (47\%) of the patients with neuropathy ( 10 anti-Hu, 1 anti-Yo, and 6 atypical antineuronal antibodies (neuronal binding in immunohistochemistry and western blot, but unknown antigen)). One patient with an atypical antineuronal antibody has been described in detail previously. ${ }^{11}$ The ANA titre was elevated in 17/36 patients (47\%; titre at least 1/200). Eight of these 17 patients $(22 \%)$ had ANA and antineuronal

\begin{tabular}{|c|c|}
\hline \multicolumn{2}{|c|}{$\begin{array}{l}\text { Table } 1 \text { Tumour types in the patients with } \\
\text { paraneoplastic neuropathy }\end{array}$} \\
\hline Tumour & $\begin{array}{l}\text { Frequency } \\
\%(\mathrm{n} / \mathrm{N})\end{array}$ \\
\hline Lung cancer (all) & $36.1(13 / 36)$ \\
\hline Small cell lung cancer & $27.7(10 / 36)$ \\
\hline Non-small cell lung cancer & $5.5(2 / 36)$ \\
\hline Carcinoid & $2.7(1 / 36)$ \\
\hline Lymphoma & $13.8(5 / 36)$ \\
\hline Breast cancer & $13.8(5 / 36)$ \\
\hline Others* & $36.1(13 / 36)$ \\
\hline \multicolumn{2}{|c|}{$\begin{array}{l}\text { *Includes: } 3 \text { prostate carcinoma, } 2 \text { ovarian cancer, } 3 \\
\text { gastrointestinal tumours, } 2 \text { sarcoma, } 1 \text { pancreatic tumour, } 1 \\
\text { melanoma, } 1 \text { kidney carcinoma. }\end{array}$} \\
\hline
\end{tabular}

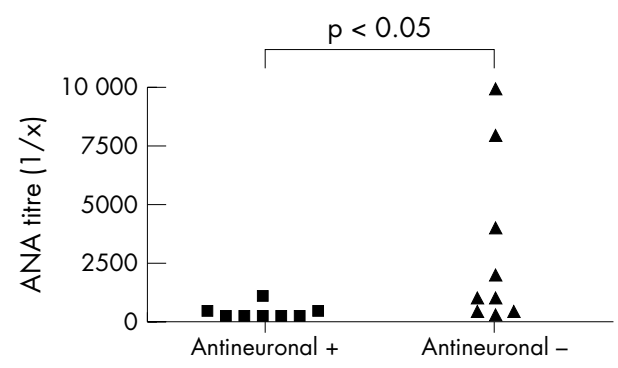

Figure 1 Comparison of antinuclear antibody (ANA) titres in paraneoplastic neuropathy with and without antineuronal antibodies. ANA titres in antineuronal negative patients are higher $(p<0.05)$.

antibodies ( 1 anti-Yo, 4 anti-Hu, 3 atypical antineuronal antibody), and nine $(25 \%)$ had high titre $(\geqslant 1 / 200)$ ANA but no antineuronal autoantibodies. The median titre in this group was $1 / 1000$ (range $1 / 200-1 / 10000$ ), whereas the median ANA titre in antineuronal antibody positive patients was $1 / 200$ (range $1 / 200-1 / 1000$ ) (fig $1, p<0.05$ ). We could not find a common binding pattern for all ANA positive/ antineuronal negative patients in a western blot using homogenised Hep-2 cells as antigens (data not shown). Analysis of the ANA fine specificities revealed SSA in one patient, histone proteins in another patient, and proliferative cell nuclear antigen (PCNA) in a third (done by an external laboratory) and no other tested reactivities in the rest (table 2). Two patients showed reactivity against the centromerprotein CENP-F. Among the patients with ANA and antineuronal antibodies, one patient had SSA and two had Sm reactivity, and our test system did not characterise the reactivities in the other patients.

\section{Clinical features of ANA positive paraneoplastic neuropathy}

We compared the clinical features of the patients who were (exclusively) ANA positive with those of the other neuropathy patients. The mean age was not significantly different (ANA positive 64.1 (9.1) years $v$ other 60.8 (10.6) years). In contrast with the ANA negative group, there was a predominance of female patients in the ANA positive group $(\mathrm{p}<0.05)$. In seven patients the neuropathy preceded the tumour (range 2-24 months), in one patient tumour and neuropathy presented simultaneously, and in another patient, the neuropathy developed 10 months after the diagnosis of the tumour. None of ANA positive patients had central nervous system (CNS) involvement but $29 \%$ of the ANA negative patients had CNS involvement (NS). Autonomic disturbances (gastrointestinal pseudo-obstruction or pathological blood pressure response in tilt table test) were less frequent, and the difference was not statistically 
Table 2 Clinical, immunological, and pathological features of the antinuclear antibody (ANA) positive patients

\begin{tabular}{|c|c|c|c|c|c|c|c|}
\hline $\begin{array}{l}\text { Patient } \\
\text { no }\end{array}$ & Symptoms & Tumour & ANA titre & $\begin{array}{l}\text { ANA } \\
\text { specificity }\end{array}$ & $\begin{array}{l}\text { Initial platelet count } \\
\left(\times 10^{3} / \mathrm{mm}^{3}\right)\end{array}$ & $\begin{array}{l}\text { Kidney } \\
\text { function }\end{array}$ & Nerve biopsy \\
\hline 1 & $\begin{array}{l}\text { Mononeuropathy multiplex: median and } \\
\text { ulnar nerve right arm, median nerve left } \\
\text { arm }\end{array}$ & Breast cancer & 1000 & SSA & 188 & Normal & $\begin{array}{l}\text { Axonal degeneration, few } \\
\text { regenerating clusters of axons, } \\
\text { no inflammation }\end{array}$ \\
\hline 2 & $\begin{array}{l}\text { Mononeuropathy multiplex: right brachial } \\
\text { plexopathy, } \dagger \text { right peroneal nerve }\end{array}$ & Breast cancer & 400 & $-*$ & 244 & Normal & Not done \\
\hline 3 & $\begin{array}{l}\text { Distal sensory and motor deficit, areflexia, } \\
\text { distal amyotrophia }\end{array}$ & Lymphoma & 200 & Histone & 415 & Normal & Not done \\
\hline 4 & $\begin{array}{l}\text { Distal sensory and motor deficit, reduced } \\
\text { deep tendon reflexes, neuropathic pain }\end{array}$ & Colon carcinoma & 10000 & $-*$ & 273 & $\begin{array}{l}\text { Slightly } \\
\text { impaired }\end{array}$ & $\begin{array}{l}\text { Reduction of myelinated fibres, } \\
\text { wallerian degeneration, no } \\
\text { inflammation }\end{array}$ \\
\hline 5 & $\begin{array}{l}\text { Distal sensory }>\text { motor deficit, reduced } \\
\text { deep tendon reflexes }\end{array}$ & Breast cancer & 4000 & $-*$ & 312 & Normal & Not done \\
\hline 6 & $\begin{array}{l}\text { Distal sensory }<\text { motor deficit, areflexia } \\
\text { of the legs }\end{array}$ & Melanoma & 8000 & $\begin{array}{l}\text { PCNA, } \\
\text { CENP-F }\end{array}$ & 258 & Normal & Not done \\
\hline 7 & $\begin{array}{l}\text { Distal sensory and motor deficit, reduced } \\
\text { deep tendon reflexes }\end{array}$ & Breast cancer & 2000 & CENP-F & 178 & Normal & Not done \\
\hline 8 & $\begin{array}{l}\text { Distal sensory }>\text { motor deficit, areflexia } \\
\text { of the legs, neuropathic pain }\end{array}$ & Breast cancer & 1000 & $-*$ & 270 & Normal & Not done \\
\hline 9 & $\begin{array}{l}\text { Distal sensory and motor deficit, areflexia, } \\
\text { distal amyotrophy }\end{array}$ & Sarcoma & 4000 & $-*$ & 334 & Normal & $\begin{array}{l}\text { Mild reduction of myelinated } \\
\text { fibres, wallerian degeneration, } \\
\text { no inflammation }\end{array}$ \\
\hline
\end{tabular}

*None of the tested reactivities (ribosomal P protein, histone, dsDNA, CENP-B, Jo-1, Scl-70, SSA, Ro52, SSB, Sm, nRNP, CENP-F) were positive and different reactivities on Hep-2 cell western blot (data not shown).

†Tumour was on the left side, which excludes metastatic infiltration of the brachial plexus

CENP-F, a centromerprotein; PCNA, proliferative cell nuclear antigen, SSA, Siögren Syndrome A.

significant (ANA positive $25 \%$, ANA negative $44 \%$ ). The differences in the underlying tumours and the types of neuropathy in the two groups are shown in table 3.

None of the ANA positive patients had clinical signs of an underlying rheumatic disease or vasculitis-that is, no patient had Raynaud's phenomenon or skin abnormalities, all had normal platelet count, and all but one patient had normal kidney function (table 2). Moreover, three patients underwent nerve biopsy, and none of them showed vasculitic features (table 2).

Interestingly, in patients with ANA positive paraneoplastic neuropathies the prognosis was better for the neurological

Table 3 Clinical and epidemiological features of antinuclear antibody (ANA) positive and negative patients

\begin{tabular}{|c|c|c|c|}
\hline & $\begin{array}{l}\text { ANA positive } \\
(\mathrm{n}=9)\end{array}$ & $\begin{array}{l}\text { ANA negative } \\
(n=27)\end{array}$ & $\mathbf{p}$ \\
\hline Men/women & $3 / 6$ & $19 / 8$ & $p<0.05$ \\
\hline Age in years, mean (SD) & $64.1(9.5)$ & $60.8(10.6)$ & NS \\
\hline CNS involvement & 0 & $8 / 27$ & NS \\
\hline Autonomic disturbances* & $2 / 8$ & $8 / 18$ & NS \\
\hline \multicolumn{3}{|l|}{ Tumour type } & \multirow[t]{7}{*}{$\mathrm{p}<0.05 \uparrow$} \\
\hline Lung & 0 & $13 / 27$ & \\
\hline Lymphoma & $1 / 9$ & $4 / 27$ & \\
\hline Breast & $5 / 9$ & 0 & \\
\hline Ovarian & 0 & $2 / 27$ & \\
\hline Prostate & 0 & $3 / 27$ & \\
\hline Othersł & $3 / 9$ & $5 / 27$ & \\
\hline PNS-tumour time interval in months & $-8.3(11.7)$ & $-3.6(14.0)$ & NS \\
\hline \multicolumn{4}{|l|}{ Treatment of the neuropathy* } \\
\hline Tumour treatment & $8 / 9$ & $17 / 20$ & NS \\
\hline Chemotherapy & $4 / 9$ & $11 / 20$ & NS \\
\hline Immunosuppressant/immunomodulatory therapy & $6 / 9$ & $11 / 20$ & NS \\
\hline \multicolumn{4}{|l|}{ Rankin score (median ( $25 \%$ and $75 \%$ percentile)) } \\
\hline At diagnosis & 2 (1.9 and 2.7) & $3(2.1$ and 3.3$)$ & NS \\
\hline After one year & 2 (1.5 and 2.5$)$ & $4(1.5$ and 5.0$)$ & $\mathrm{p}<0.05$ \\
\hline \multicolumn{3}{|l|}{ Course of the neuropathy } & \multirow[t]{4}{*}{$\mathrm{p}<0.05 \dagger$} \\
\hline Improved & $2 / 9$ & $2 / 20$ & \\
\hline Stable & $7 / 9$ & $6 / 20$ & \\
\hline Deteriorated & 0 & $12 / 20$ & \\
\hline \multicolumn{3}{|l|}{ Type of neuropathy } & \multirow[t]{5}{*}{ NS† } \\
\hline Sensorimotor & $7 / 9$ & $16 / 27$ & \\
\hline GBS/CIDP & 0 & $4 / 27$ & \\
\hline Multiplex & $2 / 9$ & 0 & \\
\hline Single system/isolated (motor/sensory/autonomic) & 0 & $7 / 27$ & \\
\hline \multicolumn{4}{|c|}{$\begin{array}{l}\text { *Information not available of all patients. } \\
\text { †Calculated by } \chi^{2}(2 \times 3,2 \times 4 \text { and } 2 \times 6 \text { tables) with Yates' correction. } \\
\text { †ANA positive colon carcinoma, melanoma, and sarcoma; ANA negative liposarcoma, pancreatic cancer, } 2 \times \\
\text { stomach cancer, kidney carcinoma } \\
\text { CIDP, chronic inflammatory demyelinating polyneuropathy; GBS, Guillain-Barré syndrome; NS, not significant; } \\
\text { PNS, paraneoplastic neurological syndrome; RS, Rankin score. }\end{array}$} \\
\hline
\end{tabular}


disease. There were no significant differences in the modified RS at the time of diagnosis between the ANA positive and ANA negative patients (median: ANA positive 2 and ANA negative 3). However, after an observation period of one year, ANA positive patients still had RS median 2, whereas in the ANA negative patients the median increased to 4, indicating a better outcome for ANA positive patients one year after the diagnosis $(\mathrm{p}<0.05$, table 3$)$.

\section{DISCUSSION}

In the present study we found that some patients with paraneoplastic neuropathy do not demonstrate antineuronal antibodies but they have high titre ANA, and these patients are clinically distinct from others with paraneoplastic neuropathies. Paraneoplastic neuropathies represent the majority of PNS. Although an increasing number of onconeural antigens has been described over the past years, only about $50 \%$ of patients with paraneoplastic neuropathy have detectable antineuronal antibodies. ${ }^{3}{ }^{4}$ Most of the antineuronal antibody positive patients have anti-Hu and sensory neuronopathy..$^{3-5}$ The others have anti-CRMP5 antibodies, which are associated with a mixed axonal and demyelinating neuropathy or ANNA-3. ${ }^{67}$ ANA are autoantibodies against ubiquitous nuclear antigens. Their role as a sensitive diagnostic tool in rheumatic diseases has been described extensively. ${ }^{12}$ However, low titre ANA have not only been found in $2-6 \%$ of healthy people, but also in other organ specific autoimmune diseases such as autoimmune thyroid disease, multiple sclerosis, and autoimmune diabetes. ${ }^{13-16}$ In recent years, an increased prevalence of ANA has also been reported in patients with tumours who do not have signs of rheumatic disease or vasculitis. ${ }^{10}{ }^{17}$ However, the ANA titres reported in these studies, including our previous study on non-small cell lung cancers, are much lower than those in the patients in our present study.$^{10}$ In these patients ANA had no common binding pattern in IFT or on a blot using recombinant or purified antigens to characterise the ANA fine specificity. However, it was surprising that only four of our patients had identifiable fine specificities (SSA, histone protein, PCNA and CENP-F). This may be because patients with tumour diseases and ANA exhibit predominantly autoantibodies against proliferation associated antigens, such as cyclins. ${ }^{18} 19$ Another study has shown that western blot reactivities against ubiquitous autoantigens in tumour patients may be able to differentiate tumour disease from other diseases. ${ }^{17}$ Although a proportion of our patients had different ANA reactivities, the high titers of the ANA support the idea that ANA may be related to the pathogenesis in some patients with paraneoplastic neurological disease. We have recently shown that ANA positive patients with non-small cell lung cancer have a better prognosis, and this has also been reported for patients with anti-Hu antibodies and small cell lung cancer. ${ }^{10} 20$

ANA in patients with paraneoplastic neurological diseases was previously reported by Moll and coworkers. They investigated patients with PNS for detectable non-organ specific autoantibodies and showed low titer ANA positivity in $34.7 \%$ of their patients. ${ }^{21}$ Because these patients were selected on the basis of a positive antineuronal antibody, these results are not directly comparable with our study. We based the selection of patients on clinical observation (tumour and otherwise unexplained neuropathy) regardless of antineuronal antibody status. We identified a group of patients with paraneoplastic neuropathy who had a different immunological pattern with high titer ANA without antineuronal antibodies. These patients also had different clinical features. Sensorimotor neuropathy was the predominant type of neuropathy, and lung cancer did not occur in these patients. Patients with antineuronal positive paraneoplastic neuropathy more often have pure sensory neuronopathy, and the predominant tumour in these patients is lung cancer. ${ }^{35}$ In our study, ANA positive/ antineuronal negative patients showed no CNS involvement, which is common in patients with antineuronal antibodies and paraneoplastic neuropathy. ${ }^{35}$

Our ANA positive/antineuronal negative patients also had a better functional outcome of their neuropathy. We cannot completely exclude that different tumour therapies may have had an impact on the course of the neurological disease. In addition, the study included only a small number of patients, and the course of the neuropathy should be evaluated in a larger group of patients with PNS. However, there was no difference between the groups in the percentage of patients receiving concomitant tumour treatment or chemotherapy. In a recent study, Graus et al analysed the clinical course of anti$\mathrm{Hu}$ positive patients and found tumour treatment to be the only independent predictor of at least stabilisation of the neurological outcome. ${ }^{22}$ This was confirmed by another study of 73 anti-Hu positive patients. ${ }^{23}$ The only large series of patients with paraneoplastic neuropathy selected from a clinical point of view (investigation for peripheral neuropathy) was reported by Antoine and colleagues. ${ }^{4}$ They described three different types of paraneoplastic neuropathy: paraneoplastic neuropathy with antineuronal antibodies (group 1), and paraneoplastic neuropathy without antineuronal antibodies either with a long latency between onset of the neuropathy and tumour diagnosis (group 2) or with a short latency (group 3). Most patients in the first and the second groups showed progressive neurological disease, whereas $50 \%$ of the patients with a short latency showed an improvement of the neuropathic symptoms. This group shares some clinical features with our patients: different clinical types of neuropathy were observed, the majority of patients had no lung cancer, and about half of the patients improved after immunotherapy. ${ }^{4}$ However, there is no information whether these patients had ANA.

Taken together, our study shows that paraneoplastic neuropathy is a clinical and immunological heterogeneous disease. Only some patients with paraneoplastic neuropathy have antineuronal antibodies. Antinuclear antibody positive patients without antineuronal antibodies may represent a clinically distinct subgroup of paraneoplastic neuropathy.

\section{Authors' affiliations}

M Tschernatsch, E Stolz, M Kaps, F Blaes, Department of Neurology, Justus-Liebig-University, Giessen, Germany

M Strittmatter, Department of Neurology, SHG Kliniken Merzig, Germany

Competing interests: none declared

\section{REFERENCES}

1 Dalmau J, Graus F. Paraneoplastic syndromes of the nervous system. In: Loeffler JS, eds. Cancer of the nervous system. Oxford: Blackwell Scientific Publications, 1997:674-700.

2 Dalmau J, Furneaux HM, Cordon-Cardo C, et al. The expression of the $\mathrm{Hu}$ (paraneoplastic encephalomyelitis/sensory neuronopathy) antigen in human normal and tumor tissues. Am J Pathol 1992;141:881-6.

3 Sillevis Smitt P, Posner JB. Paraneoplastic peripheral neuropathy. Baillière's Clin Neurol, 1995;4:443-68.

4 Antoine JC, Mosnier JF, Absi L, et al. Carcinoma-associated paraneoplastic peripheral neuropathies in patients with and without anti-onconeural antibodies. J Neurol Neurosurg Psychiatry 1999;67:7-14.

5 Dalmau J, Graus F, Rosenblum MK, et al. Anti-Hu-associated paraneoplastic encephalomyelitis/sensory neuronopathy. A clinical study of 71 patients. Medicine 1992;71:59-72.

6 Antoine JC, Honnorat J, Camdessanche JP, et al. Paraneoplastic anti-CV2 antibodies react with peripheral nerve and are associated with a mixed axonal and demyelinating peripheral neuropathy. Ann Neurol 2001;49:214-21.

7 Chan KH, Vernino S, Lennon VA. ANNA-3 anti-neuronal nuclear antibody: marker of lung cancer-related autoimmunity. Ann Neurol 2001;50:301-11. 
8 Graus F, Delattre JY, Antoine JC, et al. Recommended diagnostic criteria for paraneoplastic neurological syndromes. J Neurol Neurosurg Psychiatry 2004;75: 1135-40.

9 Keime-Guibert F, Graus F, Broet P, et al. Clinical outcome of patients with antiHu-associated encephalomyelitis after treatment of the tumour. Neurology 1999:53:1719-23.

10 Blaes F, Klotz M, Huwer $\mathrm{H}$, et al. Antineural and antinuclear autoantibodies are of prognostic relevance in non-small cell lung cancer. Ann Thorac Surg 2000;69:254-8.

11 Blaes F, Strittmatter M, Schwamborn J, et al. Antineuronal antibody associated paraneoplastic neuropathy in Hodgkin's disease. Eur J Neurol 1998;5:109-12.

12 Fritzler MJ. Clinical relevance of autoantibodies in systemic rheumatic diseases. Mol Biol Rep 1996;23:133-45.

13 Yokokawa N, Aizawa T, Ishihara $M$, et al. Presence of anti-DANN antibody in diabetes mellitus: ist relation to the duration of diabetes and diabetic complications. Metabolism 1989;38:891-4.

14 Spadaro M, Amendolea MA, Mazzucconi MG, et al. Autoimmunity in multiple sclerosis: study of a wide spectrum of autoantibodies. Mult Scler 1999:5:121-5.

15 Morita S, Arima T, Matsuda M. prevalence of nonthyroid-specific autoantibodies in autoimmune thyroid disease. J Clin Endocrinol Metab 1995:80:1203-6.
16 Azizah MR, Azila MN, Zulkifli MN, et al. The prevalence of antinuclear, antidsDNA, anti-Smand anti-RNP antibodies in a group of healthy blood donors. Asian Pac J Allergy Immunol 1996;14:125-8.

17 Fernandez-Madrid F, VandeVord PJ, Yang X, et al. Antinuclear antibodies as potential markers of lung cancer. Clin Cancer Res 1999;5: 1393-400.

18 Cassiano CA, Humbel RL, Peebles C, et al. Autoimmunity to the cell cycle dependent centromere protein $\mathrm{p} 330 / \mathrm{CENP}-\mathrm{F}$ in disorders associated with cell proliferation. J Autoimmun 1995;8:575-86.

19 Covini G, Chan EK, Nishioka N, et al. Immune response to cyclin B1 in hepatocellular carcinoma. Hepatology 1997;25:75-80.

20 Graus F, Dalmau J, Rene R, et al. Anti-Hu antibodies in patients with small-cell lung cancer: association with complete response to therapy and improved survival. J Clin Oncol 1997; 15:2866-72.

21 Moll JWB, Hooijkaas H, van Goorbergh BCM, et al. Systemic and antineuronal autoantibodies in patients with paraneoplastic neurological diseases. J Neurol 1996;243:51-6.

22 Graus F, Keime-Guibert F, Rene R, et al. Anti-Hu-associated paraneoplastic encephalomyelitis: analysis of 200 patients. Brain 2001;124:1138-48.

23 Sillevis Smitt P, Grefkens J, de Leeuw B, et al. Survival and outcome in 73 antiHu positive patients with paraneoplastic encephalomyelitis/sensory neuronopathy. J Neurol 2002;249:745-53.

\section{The James Lind Library: http://www.jameslindlibrary.org/}

W ho was James Lind and did he have a library? Educated neurologists will know the answer to this question. James Lind was the naval surgeon who discovered that citrus fruits cured scurvy. He proved this by allocating sailors on $\mathrm{HM} 4^{\text {th }}$ rate ship Salisbury to various cures of the day including vinegar, sea water, and cider, not at random but in a haphazard sort of way-in other words he used controls as a "fair test" of his ideas, although his sample size was only 12 in total! Moreover, he systematically reviewed the previous literature, albeit without the sophisticated electronic searching that throws up thousands of possibly relevant articles these days. Amazingly, over half of all the books he referred to, including his ownTreatise of the Scurvy, published in 1753-are in the library of the Royal College of Physicians in Edinburgh (RCPE).

Although James Lind almost certainly must have had a library of his own, as all serious doctors still do, the so-called James Lind Library is a web based resource, hosted by the RCPE and launched in 2003. It contains material relevant to the evaluation of "fair tests" of therapeutic interventions over the ages, from the Book of Daniel until the modern era of randomised controlled trials and meta-analysis. There are extracts of relevant books and papers, often with a commentary, a portrait, and translations where necessary - and the whole thing is growing all the time. There are also numerous essays on the modern structure of fair comparisons

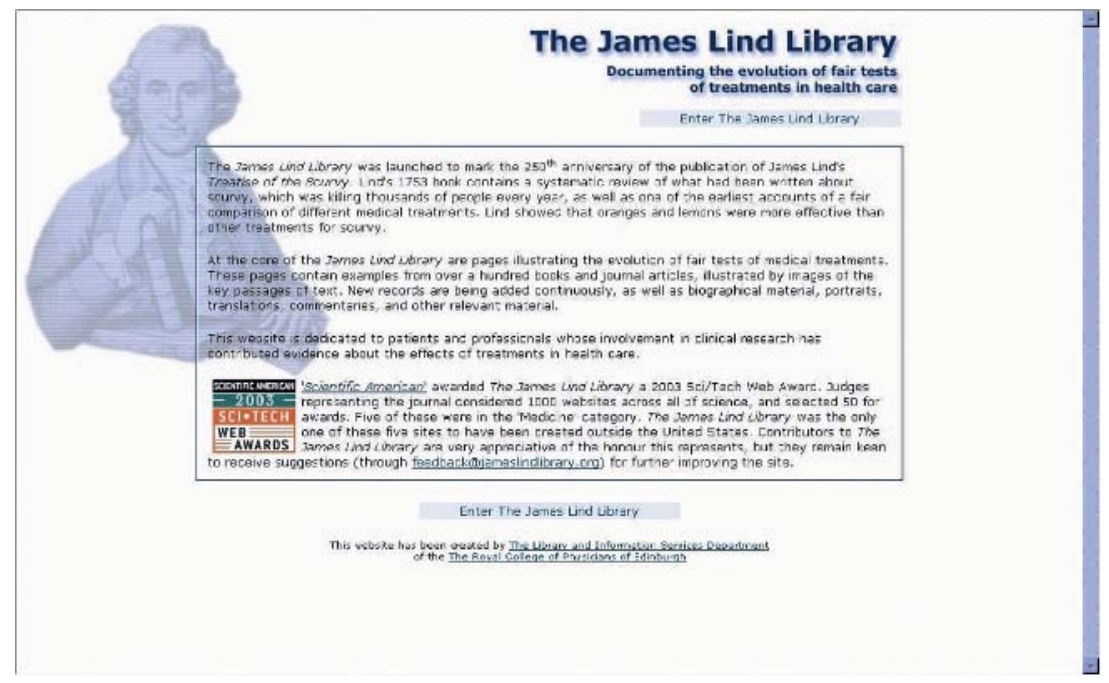

using randomised trials, their rationale, meta-analysis, and so on (but often the author is not revealed).

It comes as no surprise that the originator and editor of the library is Iain Chalmers-he who invented the Cochrane collaboration. Ever restless, and not content with just the Librarytogether with INVOLVE (www.invo.org.uk) and the Royal Society of Medicine (www.rsm.ac.uk)- he has set up the James Lind Alliance, a new coalition of organisations representing patients and clinicians collaborating to confront important uncertainties about the effects of treatments - which are the most important, how should they be identified, and how can the relevant trials be done?
Anyone with a serious interest in the evaluation of treatment interventions needs to know about this website, almost as much as they need to know about the Cochrane Library. Of course, to those of a certain age - like me having it all on paper in a nicely bound book in my very own library would be more congenial than getting my head at the right angle to allow the glasses to focus and then applying my right hand to the mouse. Click on.

Correspondence to: Prof C P Warlow, Western General Hospital, Edinburgh, UK charles.warlow@ed.ac.uk 